\title{
DEGRADATION OF PHENOL USING SEQUENTIAL BATCH REACTOR
}

\author{
Rajkumar V. Raikar ${ }^{1}$, Rekha Patil ${ }^{2}$, Arjun Virupakshi ${ }^{3}$ \\ ${ }^{1}$ Professor, Department of Civil Engineering, KLE Dr.MSSCET, Belgaum, Karnataka, India \\ ${ }^{2}$ Assistant Professor, Department of Civil Engineering, Rural Engineering College, Hulkoti, Karnataka, India \\ ${ }^{3}$ Assistant Professor, Department of Civil Engineering, KLE Dr.MSSCET, Belgaum, Karnataka, India,
}

\begin{abstract}
The paper presents the experimental study on the use of Sequential Batch Reactor (SBR) for the degradation of phenol in the synthetic wastewater. SBR was used as a biological treatment for the reduction of COD, which is based on suspended growth system. The garden soil with cow dung was used as the seeding material in SBR, the micro-organisms that are present help in degradation of phenol as well as reducing the COD concentration. The parameters varied in the study were initial concentration of phenol in the synthetic wastewater, aeration rate and hydraulic retention time. The degradation study shows that the maximum phenol removal efficiency is $97 \%$ for 200 ppm of initial phenol concentration under $40 \mathrm{ml} / \mathrm{min}$ of aeration rate. The COD removal efficiency of $92.3 \%$ is achieved for 250 ppm of concentration of phenol. The variation in the aeration rate was found to be very effective in increasing the efficiency of SBR. For $600 \mathrm{ml} / \mathrm{min}$ of aeration, the removal efficiency of phenol and COD are respectively, $98 \%$ and $75 \%$. But for the aeration rate of $200 \mathrm{ml} / \mathrm{min}$ the removal efficiency of COD is as high as $81.25 \%$. Hence, with the increase in the aeration rate, there is an increase in the degradation rate of phenol and decrease in COD reduction. This study demonstrates the utilization of SBR in degrading high concentration of phenol.
\end{abstract}

Keywords: Sequential Batch Reactor (SBR), Phenol, COD, Biological Treatment ...

\section{INTRODUCTION}

Phenol was first extracted from coal tar, but today it is produced on large scale (about 7 billion $\mathrm{kg} / \mathrm{year}$ ) from petroleum. It is an important industrial commodity as a precursor to many materials and useful compounds. Its major uses involve its conversion to plastics or related materials, its chemical derivatives in buildings, polycarbonates, epoxies, Bakelite, nylon, detergents and numerous pharmaceutical drugs.

Various industries such as oil refineries, petrochemical plant, coke conversion, pharmaceuticals and resin industries produced many toxic substance as there effluent and phenol being one of it. Phenol is most frequently found pollutant in rivers and landfills runoff water. Phenol concentration up to $10,000 \mathrm{mg} / \mathrm{l}$ has been reported in much industrial wastewater. It is one of the major pollutants found in industrial wastewater, if untreated causes greater chaos in environment. Removal of phenol can be attained by physico-chemical process (i.e. solvent extraction activated carbon adsorption, advanced oxidation process) and biological processes. Biological process is more effective and the end products formed are non toxic [1]. Many investigators studied on phenol biodegradation using pure cultures such as Pseudomonas species, acinetobacter sp, aspergillus sp and Candida sp. However, the oxidative enzymes like horseradish peroxidase and soybean peroxidase obtained from plants play an important role in phenol degradation [2].
Zinatizadeh et al. [3] used sequential batch reactors for treating stimulated dairy wastewater. The biological processes based on a suspended SBR are effective for organic carbon removal in domestic and industrial wastewater. Cassidy et al. [4] treated soil contaminated with diesel fuel in SBR with 10-day retention time under varying loading rates. The formation and characteristics of intracellular polymers in aerobic sludge of SBR were studied by Fang and Liu [5]. Khan et al. [6] used SBR for degradation of phenol from a wastewater as well as investigated the efficiency of SBR in reduction of COD. However, the influence of aeration rate on the efficiency of SBR in degradation of phenol was not studied so far. Hence, the present study deals with the application of biological treatment for the reduction of phenol, COD present in phenolic wastewater using SBR under varying aeration rates. The treatment process will be conducted using SBR based on suspended growth system.

\section{MATERIALS AND METHODOLOGY}

\subsection{Experimental Setup}

For the experimentation, a column type sequential batch reactor was fabricated in the laboratory. An $8 \mathrm{~cm}$ diameter acrylic pipe having $120 \mathrm{~cm}$ height was used to fabricate the reactor of capacity 5 liters. However, the working capacity of the reactor was 4.5 liters. Figure 1 illustrates the schematic diagram of the reactor. The reactor was open at the top and closed at the bottom. It was fitted with three outlet ports at the bottom. The lower most outlet was placed at $5 \mathrm{~cm}$ from the bottom of the reactor that facilitated in the 
removal of the sludge from the reactor. The top port, which was at $30 \mathrm{~cm}$ from the lowest port is used for the collection of the sample to study the degradation of phenol. However, the middle one $(20 \mathrm{~cm}$ below the top outlet) was used as an emergency port, in case top one is not functioning. The entire setup was fixed on a firm wooden platform. An elevated overhead tank was connected to the reactor for adding the phenol using flexible pipe. Further, an electric operated aerator system was provided in order to provide continuous aeration inside the reactor.

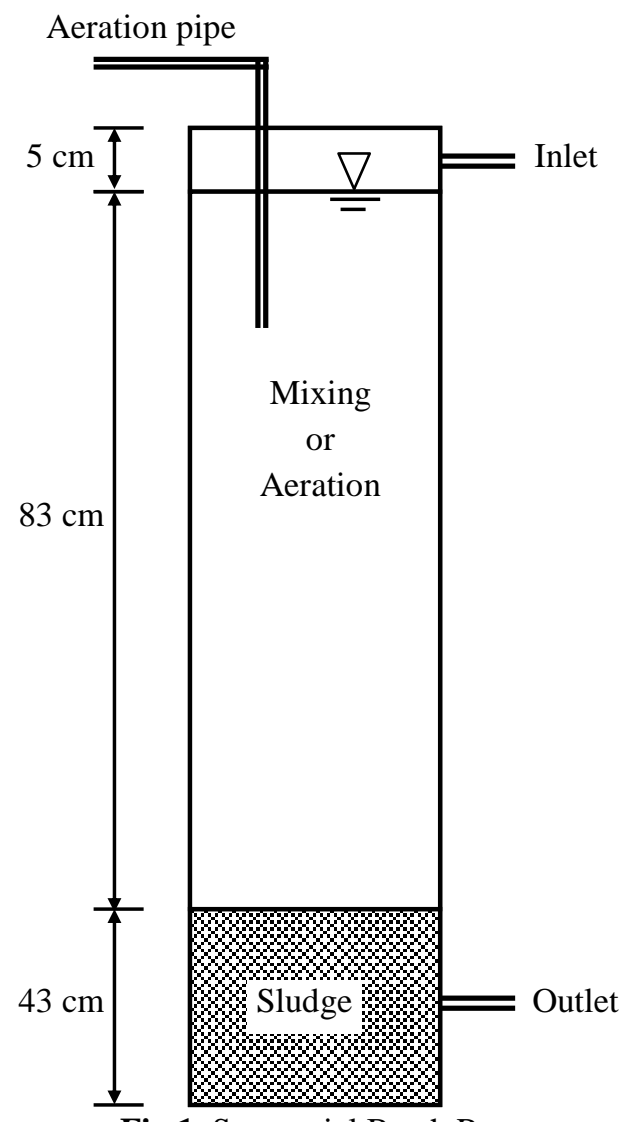

Fig 1 Sequential Batch Reactor

The reactor was operated sequentially in $24 \mathrm{hrs}$ cycle $(5 \mathrm{~min}$ of influent filing, $1415 \mathrm{~min}$ of aeration, $15 \mathrm{~min}$ for settling and $5 \mathrm{~min}$ of effluent withdrawal) to avoid excess loss of sludge. To start with, 1.5 liters of seeding material was taken in the reactor. A synthetic phenol solution of $50 \mathrm{mg} / \mathrm{l}$ was prepared and filled in the overhead tank. The phenol solution was gradually allowed to enter into the reactor from the inlet port fixed at the top until the reactor fills up to the marked level in 5 minutes. The seeding material and phenol solution were properly allowed to mix using the aerator. The rate of aeration was set at $40 \mathrm{ml} /$ minute. The sample was collected from the top outlet port for testing after time intervals of 0.5 hour, 1 hour, 1.5 hour, 2 hours, 4 hours, 8 hours and 24 hours. The collected samples were tested for phenol concentration and for COD content. Before the final sampling, last 15 minute was allowed for settling and another 5 minutes for effluent withdrawal. The same procedure was repeated with phenol concentration of 100 $\mathrm{mg} / \mathrm{l}, 150 \mathrm{mg} / \mathrm{l}, 200 \mathrm{mg} / \mathrm{l}$ and $250 \mathrm{mg} / \mathrm{l}$. Similarly, in order to study the effect of aeration on the phenol degradation efficiency of reactor, the experimental runs were carried out with aeration rates of $200 \mathrm{ml} / \mathrm{min}, 400 \mathrm{ml} / \mathrm{min}$ and 600 $\mathrm{ml} / \mathrm{min}$.

\subsection{Collection of Sample and Acclimatization of}

\section{Micro-organisms}

A 500 gm of garden soil was mixed with cow dung equivalent to $25 \%$ of garden sample proportionately as a seeding material. The garden soil is very rich source of phenolic compounds which are excreted by plants. According to Ajaz et al. [7] who isolated and identified phenol resistant bacteria from soil such as Corynebacterium species, S. aureus, proteus sp., Bacillus subtilis and Staphylococcus sp., and reported that these organisms are efficient in degrading phenol. Hence, garden soil was selected for the isolation of phenol resistant bacteria. The mixture of garden soil and cow dung was diluted with distilled water and filtered. The filtrate was added with the nutrient media consisting of chemical constituents and distilled water to form a solution of 7 liters. In the beginning, glucose and phenol were added as carbon source to the micro-organism with sufficient amount of aeration by diffused aerator. That is $1 \mathrm{ml}$ of phenol and $9 \mathrm{ml}$ of glucose in the proportion of 1:9. The sample was kept for acclimatization in a tank of 10 liter capacity for one week. Then the concentration of glucose was decreased and phenol concentration was increased gradually in the systematic manner in the proportion of $2: 8,3: 7,4: 6,5: 5,6: 4,7: 3,8: 2$ and finally 9:1 until phenol served as the sole carbon source. The addition of phenol and glucose was done after every week of acclimatization with previous dosage of phenol and glucose. Hence, the total acclimatization time was two months. From this acclimatized sample containing microorganisms, 1.5 liter was taken out and used in the sequential batch reactor for experimentation.

\subsection{Phenol Analysis}

The standard procedure of 4-Amino anti pyrine (4-AAP) method was employed in the determination of phenol concentration of the sample collected from the reactor. This method is applicable for the phenol concentration having the range of 0.5 to $5 \mathrm{mg} / \mathrm{l}$. If the sample concentration is more than $5 \mathrm{mg} / \mathrm{l}$, then the sample was diluted. In this method, $100 \mathrm{ml}$ of phenol sample was taken and $2.5 \mathrm{ml}$ of $0.5 \mathrm{~N}$ ammonium hydroxide was added. The $\mathrm{pH}$ of sample was adjusted to 7.9 by using phosphate buffer. Then $1 \mathrm{ml}$ of $2 \%$, 4-AAP was added and properly mixed, $1 \mathrm{ml}$ of $8 \%$ potassium ferri-cyanide was added and properly mixed again and optical density of the solution was measured using spectrophotometer. The wavelength of $500 \mathrm{~nm}$ was set to read the absorbance of the sample and the optical density of the sample was converted to phenol concentration using the calibration curve [8]. The percentage of phenol was calculated using the Eqs. (1) and (2).

Phenol concentration in $\mathrm{mg} / \mathrm{l}=(\mathrm{A} / \mathrm{B}) \times 1000$ 
where $A=$ phenol in sample obtained from calibration curve in $\mathrm{mg}$., $\mathrm{B}=$ original sample volume in $\mathrm{ml}$.

Percent phenoldegradation

(Initial phenolconcentraton - Residualphenolconcentraton) Initial phenolconcentraton $\times 100$

\section{RESULTS AND DISCUSSIONS}

\subsection{Degradation of Phenol with Varying Initial}

\section{Phenol Concentration and with Varying HRT}

The results on the degradation of phenol from synthetic waste water prepared with initial concentrations of $50 \mathrm{ppm}$, $100 \mathrm{ppm}, 150 \mathrm{ppm}, 200 \mathrm{ppm}$ and $250 \mathrm{ppm}$ at different time intervals of $0.5 \mathrm{~h}, 1 \mathrm{~h}, 1.5 \mathrm{~h}, 2 \mathrm{~h}, 4 \mathrm{~h}, 8 \mathrm{~h}$, and $24 \mathrm{~h}$ are discussed in this section. The results are shown in Fig. 2, which presents the degradation of phenol with increasing hydraulic retention time (HRT) for different initial concentration of phenol. For this set of experiments, the aeration rate was fixed at $40 \mathrm{ml} / \mathrm{min}$. The degradation of phenol concentration increases with an increase in HRT. It has been observed that as phenol concentration increases; there was decrease in degradation of phenol. This may be due to the reduction in bacterial count in seed which cause decreasing rate of degradation of phenol.

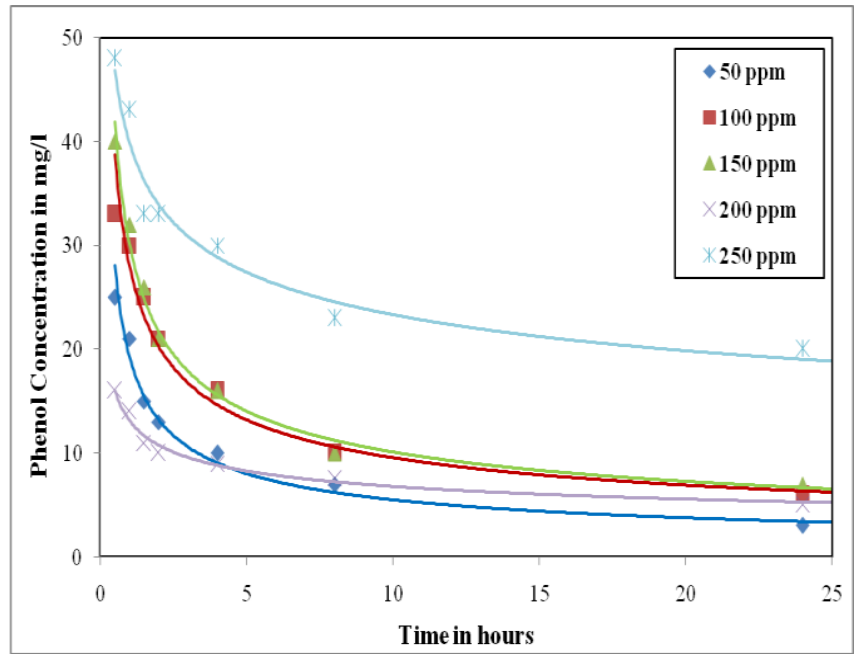

Fig. 2 Degradation of phenol for different initial phenol concentration

The percentage removal of phenol from synthetic phenol waste water prepared with initial concentrations of $50 \mathrm{ppm}$, $100 \mathrm{ppm}, 150 \mathrm{ppm}, 200 \mathrm{ppm}$ and $250 \mathrm{ppm}$ at different time intervals of $0.5 \mathrm{~h}, 1 \mathrm{~h}, 1.5 \mathrm{~h}, 2 \mathrm{~h}, 4 \mathrm{~h}, 8 \mathrm{~h}$, and $24 \mathrm{~h}$ was calculated. Fig. 3 illustrates the percentage removal of phenol with time for the respective initial phenol concentration ranging from $50 \mathrm{ppm}$ to $250 \mathrm{ppm}$ at the rate of $50 \mathrm{ppm}$. From each of these figures it can be observed that the percentage removal of phenol increases with time. However, it is important to note that at initial stages the rate of degradation of phenol is higher, while the degradation rate decreases towards the end of the cycle.
The removal of phenol at 24 hours with initial concentration of $50 \mathrm{ppm}, 100 \mathrm{ppm}, 150 \mathrm{ppm}, 200 \mathrm{ppm}$ and $250 \mathrm{ppm}$ is respectively, 94\%, 94\%, 95\%, 97\% and 92\%. Further, it is found that, percentage removal of phenol increases with an initial phenol concentration. However, at the initial concentration of $250 \mathrm{ppm}$ there is slight decrease in the removal efficiency of phenol. This is mainly due to higher availability of phenol to the micro-organism, which enhances the initial reduction higher and final degradation lower. Similar results were also observed by Pradeep et al. [1], who studied the biodegradation of phenol using rotating biological contactor.

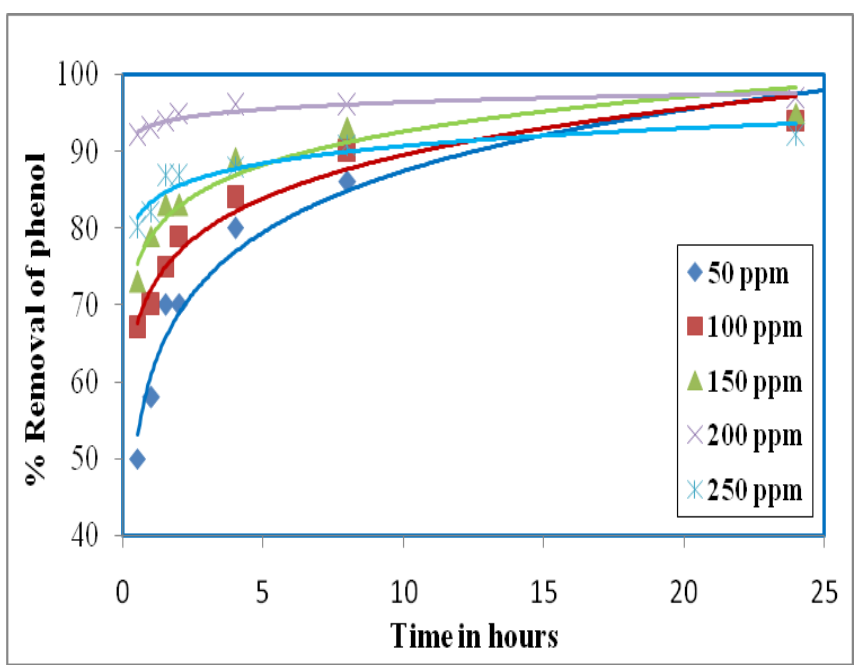

Fig. 3 Percentage removal of phenol with varying initial concentration of phenol

\subsection{Reduction of COD with Varying Initial Phenol}

\section{Concentration and with Varying HRT}

The results on the reduction in COD from synthetic phenol waste water prepared with initial concentrations of $50 \mathrm{ppm}$, $100 \mathrm{ppm}, 150 \mathrm{ppm}, 200 \mathrm{ppm}$ and $250 \mathrm{ppm}$ at different time intervals of $0.5 \mathrm{~h}, 1 \mathrm{~h}, 1.5 \mathrm{~h}, 2 \mathrm{~h}, 4 \mathrm{~h}, 8 \mathrm{~h}$, and $24 \mathrm{~h}$ are presented in this section. All the experiments were conducted with $40 \mathrm{ml} / \mathrm{min}$ of aeration rate. Fig. 4 presents the reduction in COD concentration with increasing hydraulic retention time (HRT) for different initial concentration of phenol. The COD concentration of phenolic waste water increases with an increase in HRT. In addition, it is also observed that with increase in phenol concentration; the reduction in COD concentration enhances. 


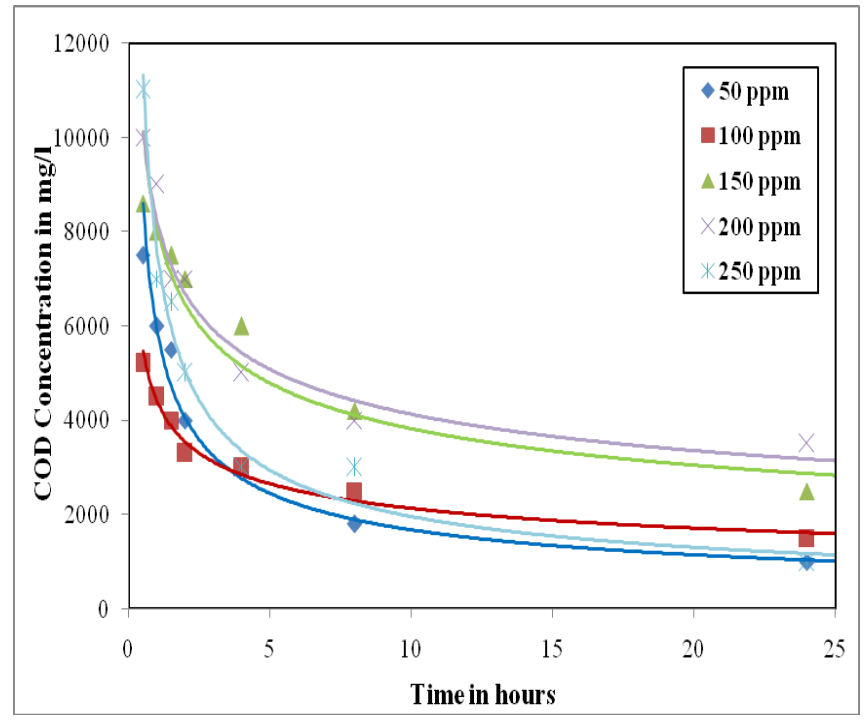

Fig. 4 Reduction in COD for different initial concentration of phenol

The percentage removal of COD present in the synthetic phenol waste water prepared with initial concentrations of $50 \mathrm{ppm}, 100 \mathrm{ppm}, 150 \mathrm{ppm}, 200 \mathrm{ppm}$ and $250 \mathrm{ppm}$ at different time intervals of $0.5 \mathrm{~h}, 1 \mathrm{~h}, 1.5 \mathrm{~h}, 2 \mathrm{~h}, 4 \mathrm{~h}, 8 \mathrm{~h}, 24 \mathrm{~h}$ was calculated. Fig. 5 presents the comparison of percentage removal of COD with HRT for the respective initial phenol concentration ranging from $50 \mathrm{ppm}$ to $250 \mathrm{ppm}$ at the rate of $50 \mathrm{ppm}$. It can be observed that the percentage removal of COD increases with time following the pattern of phenol reduction. Initially, the reduction in COD concentration is lesser, while it increases with increase in time towards the end of the cycle. The reduction in COD concentration at 24 hours with initial phenol concentration of $50 \mathrm{ppm}, 100 \mathrm{ppm}$, $150 \mathrm{ppm}, 200 \mathrm{ppm}$ and $250 \mathrm{ppm}$ is respectively, $75 \%$, $87.5 \%, 72 \%, 70.8 \%$ and $92.3 \%$. Khan et al. [6] have also reported the similar results and indicated that the reduction of COD was $94.54 \%$. This is because at high concentration of phenol, influent COD was itself high and hence high removal efficiencies are achieved.

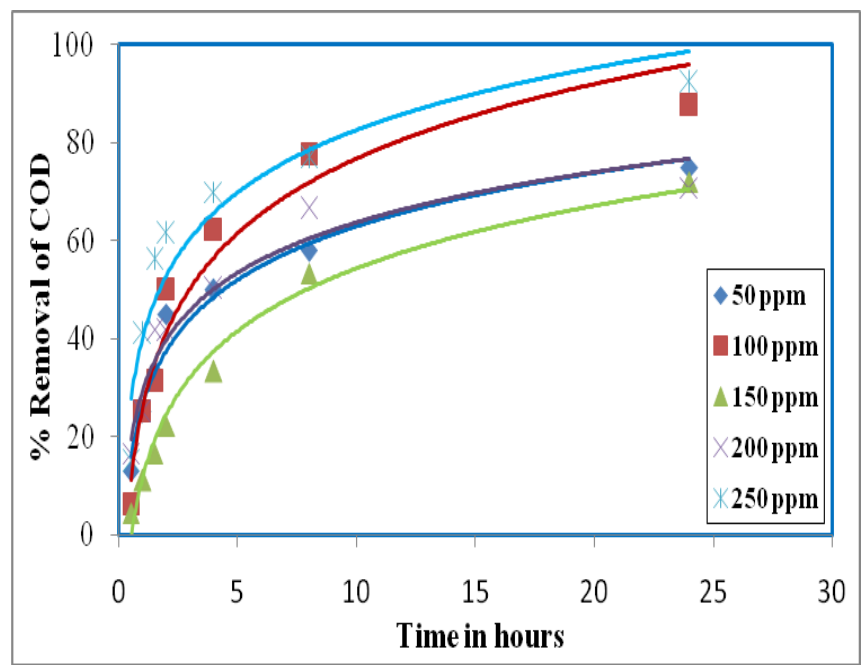

Fig. 5 Comparison of percentage removal of COD with varying initial concentration of phenol

\subsection{Effect of Aeration Rate on the Removal of}

\section{Phenol and COD}

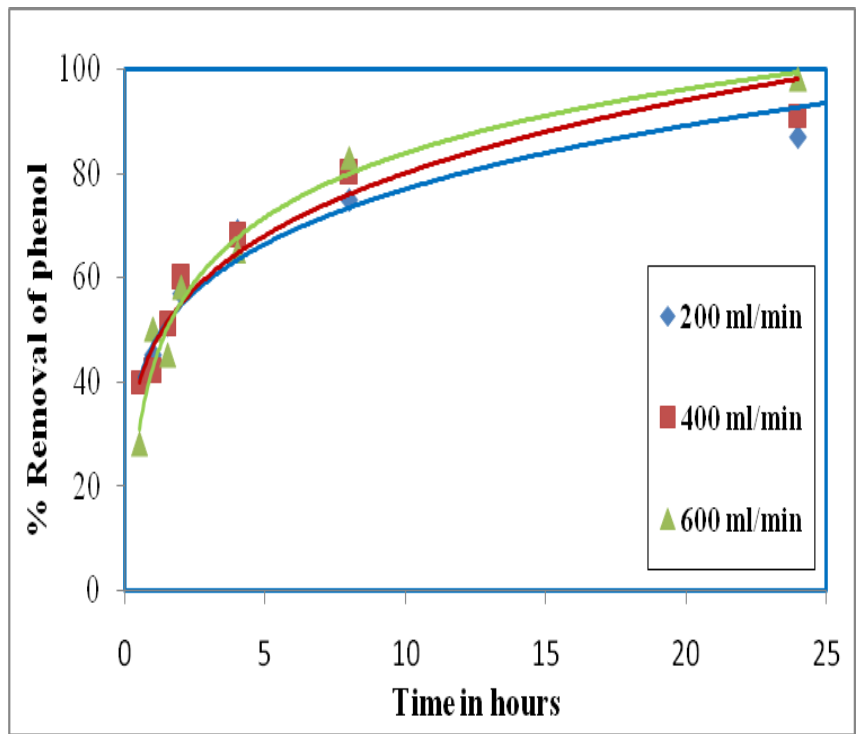

Fig. 6 Reduction in phenol at different aeration rates

To understand the effect of aeration rate on the removal efficiency of SBR, the experimental runs were taken with initial phenol concentration of $100 \mathrm{ppm}$. The aeration rate considered was $200 \mathrm{ml} / \mathrm{min}, 400 \mathrm{ml} / \mathrm{min}$ and $600 \mathrm{ml} / \mathrm{min}$. Fig. 6 shows the variation of percentage reduction in phenol with HRT at different aeration rates. It can be seen that with an increase in aeration rate the percentage removal of phenol increases. The higher aeration rate enhances the microbial activity thereby increasing the phenol reduction rate. Similar results are also obtained with COD reduction as can be evidenced from Fig. 7. Hence, in general aeration rate helps in increasing the efficiency of sequential batch reactor.

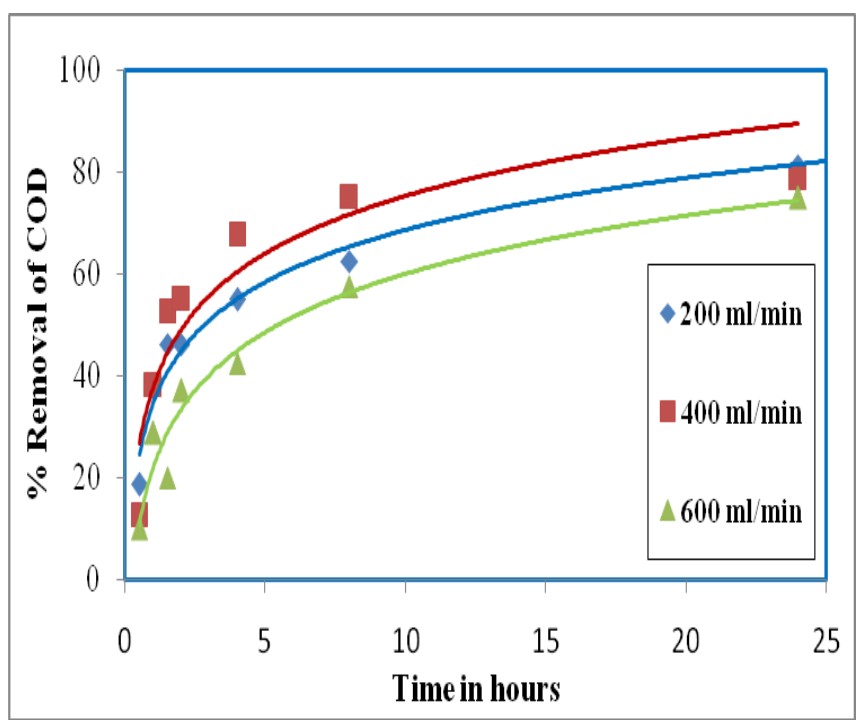

Fig. 7 Reduction in COD for different aeration rates 


\section{CONCLUSION}

The following conclusions are drawn from the present study:

1. The study demonstrates that the micro-organisms available in the garden soil along with cow dung are capable of degrading the phenol efficiently.

2. The phenol removal efficiency of $94 \%, 94 \%, 95 \%$, $97 \%$ and $92 \%$ is obtained with initial phenol concentration of $50 \mathrm{ppm}, 100 \mathrm{ppm}, 150 \mathrm{ppm}, 200$ $\mathrm{ppm}$ and $250 \mathrm{ppm}$ is respectively. It is found that the maximum percentage of removal of phenol is $97 \%$ with $200 \mathrm{ppm}$ of initial phenol concentration.

3. The reduction in COD concentration with initial phenol concentration of $50 \mathrm{ppm}, 100 \mathrm{ppm}, 150$ ppm, $200 \mathrm{ppm}$ and $250 \mathrm{ppm}$ is found be respectively, $75 \%, 87.5 \%, 72 \%, 70.8 \%$ and $92.3 \%$. The maximum efficiency of SBR in reducing COD is $92.3 \%$ with phenol concentration.

4. The increasing initial phenol concentration enhances the efficiency of SBR.

5. The aeration rate helps in increasing the efficiency of the SBR. The percentage removal of phenol is $87 \%, 91 \%$ and $98 \%$ with aeration rate of 200 $\mathrm{ml} / \mathrm{min}, 400 \mathrm{ml} / \mathrm{min}$ and $600 \mathrm{ml} / \mathrm{min}$, respectively. The corresponding COD removal efficiency is respectively, $81.2 \%, 78.7 \%$ and $75 \%$.

6. It was found that with increase in aeration rate, the SBR efficiency increases.

\section{REFERENCES}

[1] Pradeep, N. V., Anupama, K. and Hampannavar, U. S., "Biodegradation of Phenol using Rotating Biological Contactor", International Journal of Environmental Science, vol. 2(1), pp. 105-113, 2011.

[2] Rani, M. R., Sreekanth, D. and Himabindu, V., "Degradation of Mixture of Phenolic Compounds by Activated Sludge Processes Using Mixed Consortia", International Journal of Energy and Environment, vol. 2(1), pp. 151-160, 2011.

[3] Zinatizadeh, A. A., Akhbari, A., Farhadian, M., Mansouri, Y., Pirsaheb, M. and Amirsaie, R., "Influence of Process and Operational Factors on a Sequencing Batch Reactor (SBR) Performance Treating Stimulated Dairy Wastewater", International Journal of National Resources and Marine Science, vol. 1(2), pp. 111-124, 2011.

[4] Cassidy, D. P., Hudak, J. A. and Murad, A. A., "Effect of Loading in Soil Slurry-Sequencing Batch Reactors on Biosurfactant Production and Foaming", Journal of Environmental Engineering, vol. 128 (7), pp. 575-582, 2001.

[5] Fang, H. H. P. and Liu, Y., "Intracellular Polymers in Aerobic Sludge of Sequencing Batch Reactors", Journal of Environmental Engineering, vol. 126(8), pp. 732-738, 2000.

[6] Khan, F., Khan, M. Z. and Sabir, S., "Degradation Profile of Phenol in Sequential Batch Reactor", International Journal of Science and Technology, vol. 5, pp. 123-135, 2010.
[7] Ajaz, M., Noor, N., Rasool, S. A. and Khan, S., A., "Phenol Resistant Bacteria From Soil: IdentificationCharacterization and Genetically Studies", Pak. J. Bot., vol. 36(2), pp. 415-424, 2004.

[8] Patil, Rekha, "Degradation of Phenol using Sequential Batch Reactor", Master Thesis, Department of Civil Engineering, KLE Dr. M. S. Sheshgiri College of Engineering and Technology, Belgaum, 2013. 